\title{
THE EUROPEAN UNION AND E-COMMERCE
}

\author{
Arno R. Lodder and Andrew D. Murray
}

\begin{tabular}{llrllr}
\hline 1.1 & INTRODUCTION & 1.01 & 1.3 & OVERVIEW OF THE BOOK & 1.19 \\
& FROM THE PHYSICAL TO ONLINE AND & & 1.4 & FOCUS & 1.32 \\
& 1.14 & & & \\
\hline
\end{tabular}

\subsection{INTRODUCTION}

The European Union has a long history of investment in, encouragement for, and development of, electronic commerce and for more than 20 years has established a strong, and mostly coherent, regulatory framework for the e-commerce sector. We can date the EU's interest in e-commerce to at least the November 1996 Communication from the Commission Putting Services to Work. ${ }^{1}$ However that early interest from the Commission took a while to infiltrate further into EU institutions. In the report of their 13/14 December 1996 Dublin meeting ${ }^{2}$ the European Council noted the Putting Services to Work Communication in the addendum to the report, but failed to mention e-commerce in the body of their report. The Council instead focused on traditional communications services and indicated, 'Postal services form an essential component of the communications infrastructure in the Union. The development of the internal market for postal services bears huge significance in economic and social terms.' ${ }^{3}$

In April 1997 the European Commission took forward the Putting Services to Work Communication and issued their now well-known initiative 'A European Initiative on Electronic Commerce'. ${ }^{4}$ That opened with the now familiar strong statement of intent:

1 CSE(96)6 final of 27 Nov 96. The actual document is not easy to find today. We could not find it on the European Union website, nor did Google provided us with this document.

2 DOC/96/8, Dublin European Council 13 and 14 December 1996, Presidency Conclusions.

3 Ibid., Title III, Employment.

4 'A European Initiative on Electronic Commerce', COM(97) 157 final, 16.4.1997. 
The aim of this Initiative is to encourage the vigorous growth of electronic commerce in Europe. In the Communication 'Putting Services to Work' the fundamental importance of electronic commerce was emphasised, as was the Commission's commitment to make Europe the heartland of electronic commerce.

1.03 For the first time the Commission stated its intent to: 'encourage the vigorous growth', recognized the 'fundamental importance of electronic commerce in Europe', and envisioned for the European Union to become 'the heartland of electronic commerce'. These undeniably high expectations have not all been realized. For instance, the observation that 'Electronic commerce makes it possible to trade at low cost across regions and national frontiers' seems obvious, but if there is one point that over the years keeps recurring in Communications, Directives and Regulations, it is the lack of cross-border market in e-commerce. ${ }^{5}$ Another, related point, not yet confronted, concerns the delivery of goods bought online. This was mentioned specifically in the 1997 e-commerce initiative: 'the development of efficient distribution channels and trans-European network is necessary for the physical delivery of goods ordered electronically, including efficient, modern postal services'. Despite this intent, and despite some measures to protect consumers found in the Distance Selling Directive (Directive 97/7 EC) and the Consumer Rights Directive (Directive 2011/83/EC), cross-border delivery of goods bought online remains underdeveloped. Perhaps this hurdle is about to finally be removed, as in May 2016 the European Commission proposed a Regulation on cross-border parcel delivery services. ${ }^{6}$ The objectives of this proposed Regulation on parcel delivery are:

(1) make markets work more effectively by

(a) making the regulatory oversight of the parcels markets more effective and consistent and

(b) encouraging competition; and

(2) increase the transparency of tariffs in order to

(a) reduce unjustifiable tariff differences and

5 See for instance from 2007, 2012 and 2015, respectively Consumers: Commission acts to boost confidence in digital world, 8.2.2007, IP/07/158: 'All the evidence is that consumers are not yet "comfortable" enough in the digital and online world to seize its full potential. Only a tiny fraction - 6 per cent of EU consumers - are currently shopping online cross border.' A coherent framework for building trust in the Digital Single Market for e-commerce and online services, 11.1.2012, $\operatorname{COM(2011)~942:~'The~practical~difficulties~related~to~cross-border~transactions~}$ (payments, deliveries, dispute resolution, risk of abuse) discourage people from taking full advantage of the internet to purchase or supply their goods and services', and A Digital Single Market Strategy for Europe, 6.5.2015, $\mathrm{COM}(2015) 192$ final: 'One of the reasons why consumers and smaller companies do not engage more in cross-border e-commerce is because the rules that apply to these transactions can be complex, unclear and may differ between Member States.'

$6 \operatorname{COM}(2016) 285$ final, 25.5.2016. 
(b) lower the tariffs paid by individuals and small businesses, especially in remote areas. ${ }^{7}$

We will have to see what the Regulation will bring, and how it might also contribute to the other point mentioned, the need to drive an increase in cross-border e-commerce if we are to see a truly single e-commerce market. We doubt, however, whether delivery costs are the main reason cross-border e-commerce has not yet taken off in the way it was expected to in 1997. Consumers' preferences for local providers can be attributed to a number of reasons not related simply to costs.

First, there is the application of the recognition heuristic. This heuristic, or mental shortcut, was first recognized by Gerd Gigernzer and Daniel Goldstein and may be defined as: 'if one of two objects is recognized and the other is not, then infer that the recognized object has the higher value'. ${ }^{8}$ It is this heuristic that fuels advertising spend to increase brand recognition and which leads to newspapers being filled by commentators from the same few universities such as Harvard, Oxford or Cambridge. We recognize and value comment from professors at Oxford and Harvard. We, the readers, attach less value to comments from professors at the University of Derby or Missouri Western State University due to their lower 'brand recognition'. The heuristic is equally powerful online leading a UK consumer to be more likely to purchase from Argos (a UK retailer) while a Dutch consumer is more likely to purchase from HEMA (a Dutch retailer). It is the lack of a pre-existing recognition heuristic for certain online activities (such as the purchase of books or a C2C marketplace) that allowed American multinationals Amazon and eBay to dominate across markets in a way established suppliers simply could not.

Secondly there are linguistic barriers. While a website in English may be accessible across Europe, websites in less commonly exported languages such as Greek, Portuguese or Dutch are unlikely to have reach much beyond national borders. The development of linguistic translation tools such as Google translate have to date been slow and still quite ineffectual, and, while a reader of a newspaper may rely upon Google translate to read a news story, people are slower to trust translated e-commerce sites where slight nuances in language can have major impact on contractual terms.

7 Ibid., 1.2 .

8 G. Gigerenzer, P.M. Todd and the ABC Research Group, Simple Heuristics that Make Us Smart (Oxford, OUP, 1999), 41. 
1.07 Thirdly (outside the Eurozone) there are transactional costs. Thus for a UK citizen buying from a German website there will be a foreign exchange fee to pay on a Sterling account. The same is true of a Swedish citizen buying from Finland or a Polish, Czech, Hungarian, Croatian or Romanian citizen buying from each other or from Germany, Slovakia or Slovenia. The cost of delivery or of returning an item is thus not usually determinative. ${ }^{9}$ Returning an item is not a problem for the consumer, as often the supplier bears these costs. For example when one of the authors bought a product from Philips and then indicated that he wanted to return a $€ 15$ item on the basis of his legal right of return, Philips offered to allow him to keep the item for free. ${ }^{10}$ The reason probably was because it was shipped from Poland to the Netherlands, and the seller considered the cost of returning the item back to Poland too high to support. ${ }^{11}$ This situation may in future be handled differently if the transport tariffs are lowered due to the proposed Regulation.

1.08 The 1997 Initiative also aimed at stimulating e-commerce, and contributing to harmonization. ${ }^{12}$ Many of the Directives and Regulations discussed in this book, have this dual purpose. From the background of developing and growing the internal market, the already mentioned stimulation of cross-border trade is an important objective. One way to contribute to economic growth, via e-commerce, is to have a clear legal framework in place. ${ }^{13}$ In the late 1990s trust was seen as the key issue in this context. Individuals going online, both consumers and businesses, were entering a new environment where they were no longer trading face to face with their counterparties. Although there had been an element of remote business through telephone trading and mail order trading, the Internet magnified this in several ways. First, despite our earlier misgivings about the level of success in this regard, it clearly allowed for a far greater magnitude of cross-border trading, especially for consumers. Secondly, it allowed for a single platform to be employed where ordering, contracting and payment could all be organized on a 'one-click' system. Thirdly, location and identity could be shielded or 'spoofed' much more easily than with

9 These being the costs directly regulated by the Distance Selling and Consumer Rights Directives.

10 On the condition he did not resell it, and if he threw it away did so in an environmentally friendly way.

11 Although legally you do not have to provide a reason for returning (see Chapter 7), the reason for returning was that from the picture on the site it was not immediately clear knives were lacking.

12 In the words of the Commission: 'an urgent need to engage in an early political debate with the aim to provide a stimulus to electronic commerce and to avoid a fragmentation of this promising market'.

$13 \mathrm{Cf}$, the Commission:

The Single Market framework has proved its worth for traditional forms of businesses. It must be now made to work for electronic commerce. Building trust and confidence among businesses and consumers implies the deployment of secure technologies (such as digital signatures, digital certificates and secure electronic payment mechanisms) and of a predictable legal and institutional framework to support these technologies. 
traditional telephone and mail order systems (where a fixed telephone number or address could easily be located). Even today with consumers accustomed to trading online there remain trust issues. In fact, little seems to have changed between 2000 when an IPSOS-MORI poll reported, 'Twenty-eight per cent of Internet users say they would look for a recognized brand name. While 22 per cent would feel safer shopping on the site of a high-street retailer' and that 'almost four out of ten adults see the need to release credit card details as a major disadvantage of Internet shopping. Among Internet users, more than half feel the same way'14 and more recent reports that 'one third of the UK consumers said they provide fake information to protect their privacy online and data security represents a strong commercial driver for $89 \%$ of UK shoppers', 15 that ' $49 \%$ of UK consumers are worried their data is not safe' 16 and that, 'One in three UK internet users are not yet shopping online. Of these, 30\% identified lack of trust as the main factor holding them back, whilst $20 \%$ cited fears over personal security and 15\% said they did not trust companies that sell online.' 17 These figures must make for sombre reading in Brussels where nearly 20 years of e-commerce regulation has been designed to bolster trust and cross-border trade.

This may, at least partially, be attributed to the fact that there remains fragmentation in legal regimes across the European Union due to local interpretation of Directives passed under the Initiative. This may be why we are witnessing a rise in the application of Regulations in this field. In 2002, when the first edition of this book appeared, it discussed only Directives. There were at that time no relevant Regulations. Today though that model has changed and we may say that Regulations are now the driving force behind e-commerce law in the EU. Directive 97/7 EC (the Distance Selling Directive) has been replaced by Directive 2011/83/EC (the Consumer Rights Directive), Regulation No 910/2014 (the eIDAS Regulation) has replaced Directive 1999/93/EC (the E-Signatures Directive) and Regulation No 524/ 2013 (the Online Dispute Resolution Directive) has supplemented Directive 2013/11/EU (the Alternative Dispute Resolution Directive). Another recent example where a Regulation has been favoured over a Directive is the General Data Protection Regulation (Regulation (EU) 2016/679), which although not strictly an e-commerce provision is at the heart of all e-commerce activity.

14 https://www.ipsos-mori.com/researchpublications/researcharchive/1603/ECommerce-Lack-Of-ConsumerTrust-Holds-It-Back.aspx (2 August 2000).

15 http://www.computerweekly.com/news/2240241132/UK-consumers-lack-confidence-in-data-protectionstudy-finds (24 February 2015).

16 Ibid.

17 http://www.trustedshops.co.uk/news/trust-e-commerce-internet-shopping-oft-consumer-protection/ (26 May 2009). 
Whether Regulations with their direct effect actually realize the harmonization hoped for, and the creation of a true single digital market within the $\mathrm{EU}$, is yet to be seen. However the current authors remain sceptical that this will occur until the underlying issue of recognition, linguistic barriers and transactional costs are met.

1.10 This scepticism is fed by the fact that we have had almost 20 years' worth of Directives and Regulations in this area with little change in the public perception of e-commerce. In between the present Digital Single Market Strategy for Europe (2015) 18 and the 1997 E-commerce initiative there have been frequently announced initiatives including:

- eEurope - An information society for all (1999); ${ }^{19}$

- eEurope 2002 - Impact and Priorities (2001);20

- eEurope 2005 - action plan: an information society for everyone (2002); 21

- A coherent framework for building trust in the Digital Single Market for e-commerce and online services (2012).22

1.11 The objective in the last mentioned initiative was among others to double the number of e-commerce transactions between 2012-15 and undeniably, in this period e-commerce has taken off. On a worldwide scale the number of e-commerce transactions increased by 80 per cent between 2011 (21.3 billion) and 2015 (38.5 billion). ${ }^{23}$ However growth in the EU seems to be slower than elsewhere. Eurostat data on e-sales and e-purchase as a percentage of total turnover show that between 2011 and 2014 e-purchases as a percentage of total EU purchases rose from 34 to 40 per cent while e-sales as a percentage of total EU sales rose from 16 to 19 per cent. ${ }^{24}$ These represent relative rises of 17.6 per cent and 18.75 per cent, suggesting that e-commerce growth is driven more by external technological factors than by the legal measures adopted in the EU to create a single digital market. The next stage will be to implement the Digital Single Market Strategy. This is founded upon three pillars:25

http://www.statista.com/statistics/369333/number-ecommerce-transactions-worldwide/.

24 EuroStat, 'E-commerce statistics': http://ec.europa.eu/eurostat/statistics-explained/index.php/E-commerce statistics.

$25 \operatorname{COM}(2015) 192$ final, 3-4. 
1. better access for consumers and businesses to online goods and services across Europe - this requires the rapid removal of key differences between the online and offline worlds to break down barriers to crossborder online activity;

2. creating the right conditions for digital networks and services to flourish - this requires high-speed, secure and trustworthy infrastructures and content services, supported by the right regulatory conditions for innovation, investment, fair competition and a level playing field;

3. maximizing the growth potential of our European Digital Economy this requires investment in ICT infrastructures and technologies such as Cloud computing and Big Data, and research and innovation to boost industrial competiveness as well as better public services, inclusiveness and skills.

The Commission has identified 16 actions that have to contribute to realizing these aims. ${ }^{26}$ They are themed to support the three pillars. The first group of actions, to support pillar one, are: (1) to propose rules to make cross-border e-commerce easier (including harmonized EU rules on contracts and consumer protection); (2) to enforce consumer rules more rapidly and consistently by reviewing the Regulation on Consumer Protection Cooperation; (3) to propose more efficient and affordable parcel delivery (see the aforementioned proposed Regulation on cross-border parcel delivery services); (4) to end unjustified geo-blocking; (5) to identify potential competition concerns affecting European e-commerce markets; (6) to propose a modern, more European copyright law; (7) to review the Satellite and Cable Directive to assess if its scope needs to be enlarged to broadcasters' online transmissions and to explore how to boost cross-border access to broadcasters' services in Europe; and (8) to reduce the administrative burden businesses face from different VAT regimes. The second group of actions support pillar two. These are: (1) to present an ambitious overhaul of EU telecoms rules including more effective spectrum coordination, and common EU-wide criteria for spectrum assignment at national level; (2) to review the audiovisual media framework to make it fit for the twenty-first century (see the proposed Audiovisual Media Services Directive COM/2016/0287 final); (3) to comprehensively analyse the role of online platforms (search engines, social media, app stores, etc.) in the market; (4) to reinforce trust and security in digital services; and (5) to propose a partnership with the industry on cybersecurity in the area of technologies and solutions for online network security. The final group of actions support pillar three. They are: (1) to propose a 'European free flow of data initiative' to promote the free movement of data in the European Union; (2) to define priorities for standards

http://europa.eu/rapid/press-release_IP-15-4919_en.htm. 
and interoperability in areas critical to the Digital Single Market, such as e-health, transport planning or energy (smart metering); and (3) to support an inclusive digital society where citizens have the right skills to seize the opportunities of the Internet and boost their chances of getting a job.

1.13 These actions will do much to remove the legal and administrative red tape, which may affect the ability of online businesses to trade across EU state borders. They will also ensure that technological barriers such as geo-blocking are removed. However the cultural and linguistic barriers will remain. In the coming years it will become clear how successful this strategy has been.

\subsection{FROM THE PHYSICAL TO ONLINE AND BACK AGAIN}

1.14 When we discuss the early days of e-commerce, reference is often made to both the origin of the World Wide Web, and Amazon.com as one of the first online web stores. We must remember that e-commerce is still in its infancy. While the Internet will celebrate its 50th birthday in 2019 the first e-commerce site and transaction is usually recorded to the Pizzahut.com site set up in 1994 and which served pizzas to customers in Santa Cruz, California. More recently however research suggests it was actually a CD of Sting's Ten Summoner's Tales sold on August 11, 1994 (the same month Pizzahut.com was set up) on the site NetMarket. ${ }^{27}$ This means e-commerce is a little over 20 years old and is thus the much younger sibling of the Internet (and also the World Wide Web). To explain the relative infancy of e-commerce one must remember that the original networks were built upon the ARPAnet backbone, which was a government funded network and as such was restricted to non-commercial uses such as research; unrelated commercial use was strictly forbidden. It was only in 1995, after NetMarket and Pizza Hut, that full commercial use of the Internet was allowed with the creation of the private network architecture we use today. Prior to this the NSFNet acceptable use policy had precluded the use of the network for commercial purposes (although with relaxations in the application of the non-commercial use policy from as early as 1991).

1.15 Additionally, until the mid-1980s IP addresses had to be entered when accessing a remote computer. ${ }^{28}$ The adoption of domain names made it easier

27 See M. Grothhaus, 'You'll Never Guess What The First Thing Ever Sold On The Internet Was' Fast Company 26 November 2015: http://www.fastcompany.com/3054025/fast-feed/youll-never-guess-what-thefirst-thing-ever-sold-on-the-internet-was.

28 The first registered .com domain name was symbolics.com registered on 15 March 1985. The first registered domain name appears to be Nordu.net registered on 1 January 1985. 
to get in contact with a computer at a different location, but on their own they were difficult to use unless you knew exactly the location of the information you were looking for. It was not until the development and release of the World Wide Web in the early 1990s and in particular the introduction of the first Web browser, Mosaic, that the idea of e-commerce as we now know it could develop. When new technologies become successful, as in this case the Web, people aim to profit from this success by developing business ideas (or, on the dark side, criminal schemes). That is how e-commerce as we know it today originated. The hyperlinks used to connect computers are what created the World Wide Web, but without domain names and browsers the Web would not have reached the widespread consumer adoption we see today.

Among the first popular e-commerce activities were online bookstores, CD stores (e.g., NetMarket and CDnow), and travel agencies including sites operated by airlines. It is in these areas we also first witnessed from the vantage point of the offline world, the success of online sales. Book and CD stores in the real world closed their doors, and so too did a large number of travel agencies. ${ }^{29}$ An area that is presently very successful in e-commerce is the ordering of take away food, and meal preparation (such as Hello Fresh). Food and e-commerce share a history. As we have already seen Pizzahut.com was among the very first domain names to be used for e-commerce in August 1994, allowing people in Santa Cruz to order pizzas online. Also, in 2010 the first bitcoin transaction, the well-known crypto currency that started in early 2009 to pay for physical goods, was an order for pizza. Then 10,000 bitcoins were needed to get two pizzas to your home. Currently (14 June 2016) this equates to over $\$ 7.5$ million, we hope the pizza was good. ${ }^{30}$

Initial e-commerce success has allowed e-businesses to diversify. Whereas Amazon started as an online bookstore, over the years it became an online warehouse retailer offering a wide variety of products, and more recently has become one of the largest cloud services providers. Another big player is Alibaba.com. Although primarily active in China, Yahoo! bought a 15 per cent stake in the company in 2012 for $\$ 7.6$ billion, now valued in excess of $\$ 30$ billion. What is interesting about Alibaba is that they are more diversified

29 Large bookstore chains such as Borders closed down, as did Crown Books, Dillon's and Ottakers. Similarly music chains closed such as Tower Records, Virgin Megastores and HMV. See also M. West 'Travel agent closures rise $45 \%$ in a year despite rising number of holidaymakers as they opt for DIY trips over packages', Daily Mail 14 April 2014: http://www.thisismoney.co.uk/money/news/article-2604177/Travel-agentclosures-rises-45-year-despite-rising-number-holidaymakers-opt-DIY-holidays-packages.html.

30 E. Mack, 'The Bitcoin Pizza Purchase That's Worth $\$ 7$ Million Today' Forbes 23 December 2013: http://www.forbes.com/sites/ericmack/2013/12/23/the-bitcoin-pizza-purchase-thats-worth-7-million-today/. 
than Amazon, as they offer in addition to the usual warehouse retail experience a consumer-to-consumer sales site similar to 'eBay' and operate a proprietary payment system Alipay. ${ }^{31}$

1.18 More recently e-commerce sites have begun to diversify into bricks and mortar. In 2016 Amazon returned to its roots, but in an unexpected way: it announced plans to open 300-400 physical bookstores ${ }^{32}$ following early success of its Seattle's University Village store which opened in November 2015. This is part of a trend known as omni-channel: the use of a variety of channels in a customer's shopping experience including the period of research before a purchase. Channels include retail stores, e-commerce, $\mathrm{m}$-commerce, mobile apps and telesales. Transacting includes browsing, buying, returning as well as pre-sale and after-sale service. Almost all offline stores have in recent years created websites with at least company information, but normally also with the option to buy online. As traditional bricks and mortar stores are gradually disappearing from city centres, these locations find themselves being filled by service and support centres for popular e-commerce stores. Again Amazon finds itself at the forefront of this but another example is Samsung support centres, set up by the Korean electronics manufacturer to provide local support for users of Samsung devices. These centres, unlike Apple stores, sell no products. ${ }^{33}$

\subsection{OVERVIEW OF THE BOOK}

1.19 Against the backdrop of this fluid and dynamic economic, social and regulatory framework lawyers, both in practice and in academia, are often asked to explain the regulatory framework. In such a complex and fast moving arena asking any one lawyer to remain informed of the entire legal-regulatory framework seems unreasonable. For this reason we asked a series of contributors to each provide a chapter within their area of expertise to provide an invaluable single resource for lawyers, academics, students and businesses both already within and entering the European e-commerce marketplace.

1.20 Following on from this introductory chapter, the most important EU initiatives relevant to e-commerce are discussed. Some of these may be labelled as pure e-commerce provisions; some have a broader scope. In the latter case the

31 https:/www.sec.gov/Archives/edgar/data/1577552/000119312514184994/d709111df1.htm.

32 http://www.computerworld.com/article/3030321/e-commerce/this-is-why-amazon-will-open-physical-book stores.html.

33 http://www.samsung.com/uk/support/support-centres/. 
discussion in the chapter only touches upon the other issues and focuses the discussion on the part that is relevant for e-commerce.

Chapter 2 - Directive 2000/31/EC on e-commerce (The e-Commerce 1.21 Directive). This chapter by Arno R. Lodder (Vrije Universiteit Amsterdam) deals with the oldest extant e-commerce-related Directive, and arguably the most important one. Sometimes referred to as the Mother Directive, or Framework Directive. The Directive discusses establishment of information society service providers, for short e-commerce providers, and their exemption from liability. Other areas covered are among others information requirements, contractual aspects, commercial communications.

Chapter 3 - Directive 2001/29/EC on copyright (The Copyright and Related Rights Directive). Tatiani Synodinou (University of Cyprus) discusses this Directive on copyright and related rights in the information society, often referred to as the Information Society Directive. In 2002 Michel Vivant ended his chapter on this Directive with:

[the] most peculiar aspect is not, to my mind, the effect of harmonisation but the fact that it singularly avoids any harmonisation! (...) How then can this be a 'single market' of Treaties when the rules are radically different? How can we play the same game when the teams do not use the same rules? 'Much ado about ... little'? Let us hope not!'34

The new chapter discusses the Directive and how it has evolved over the years and demonstrates the Directive did have impact.

Chapter 4 - Directive 2004/48/EC on IP enforcement (The Enforcement Directive). Yin Harn Lee (Sheffield University) not only guides us through the Articles of the Directive on the enforcement of intellectual property rights, but also provides an insightful analysis of the history behind this Directive. He discusses how the initial objectives gradually disappeared into the background and the Directive became the present often-debated regulatory instrument.

Chapter 5 - Directive 2006/123/EC on services (The Services Directive). 1.24 Giovanna De Minico (University of Naples 'Federico II') and Miriam Viggiano (Italian Data Protection Authority) analyse the parts of the Services Directive relevant for e-commerce. The scope of this Directive is broad, as is clear from the statement in the opening recital, 'The European Community is

34 M. Vivant (2002), Chapter 5 Directive 2001/29, in: A.R. Lodder and H.W.K. Kaspersen (eds), eDirectives, Kluwer Law International, 117. 
seeking to forge ever closer links between the States and peoples of Europe and to ensure economic and social progress.' The authors conclude that the Directive has not, yet, achieved its objectives.

1.25 Chapter 6 - Directive 2009/110/EC on e-money and Directive 2015/ 2366/EU on payment services (The e-money Directive and the second Payment Services Directive). There is no business like e-business, a colleague used to say. The nature of money involved in doing business, online as well as offline, is gradually getting more electronic. Christina Riefa (Brunel University) provides an insightful overview of the EU initiatives from over the years addressing both e-money and payment services. The topic is complex, as for instance illustrated by the 117 Articles of Directive 2015/2366 on Payment Services, but are clearly explained in this chapter.

1.26 Chapter 7 - Directive 2011/83/EC on Consumer Rights (The Consumer Rights Directive). Unlike the proposed Directive on in particular conformity of goods, that only covers online trade; 35 the Consumer Rights Directive 2011/83/EC covers both business with consumers on premises and at a distance, including online. Christiana Markou (European University, Cyprus) focuses on the parts relevant for e-commerce, and clearly discusses all the ins and outs.

1.27 Chapter 8 - Directive 2013/11/EU on Alternative Dispute Resolution and Regulation No. 524/2013 on Online Dispute Resolution (The ADR Directive and the ODR Regulation). As long ago as 2000, Article 17 of the e-commerce Directive addressed out of court dispute settlement, including online dispute resolution. Some 13 years later the EU issued both a Directive on Alternative Dispute Resolution and a Regulation on Online Dispute Resolution. Pablo Cortes (Leicester University) addresses the requirements imposed upon providers of ADR services, and the electronic access to their services they should offer. In addition, the Regulation in which a platform on ODR is introduced is discussed.

1.28 Chapter 9 - Regulation No. 910/2014 on Electronic Identification and Trust Services (The e-IDAS Regulation). After 15 years the original Directive on electronic signatures has been replaced by the e-IDAS Regulation. Jos Dumortier (Time.lex Belgium) critically assesses both parts of the Regulation. The first part deals with electronic identification that can be used for cross-border public services. The second part introduces next to the already

35 Proposal for a Directive on certain aspects concerning contracts for the online and other distance sales of goods, 9.12.2015, COM/2015/0635 final. 
known electronic signature legal norms for four newly introduced services, viz. electronic seals, time stamps, registered delivery services as well as web authentication services.

Chapter 10 - Directive 2014/26/EU on the Collective Management of Rights (The Collective Rights Management Directive). The 28 mini markets, as the Member States in EU represent in communications and e-commerce, are of particular impact in the entertainment industry, most particularly in the music industry. Dinusha Mendis (Bournemouth University) takes us from the Paris café Ambassadeurs in 1847 to the present Internet age. This Directive 2014/ 26/EU on Collective Management of Copyright and Related Rights and Multi-Territorial Licensing of Rights in Musical Works for Online Use in the Internal Market, deals both with the organizations behind collective rights management as well as the related licences.

Chapter 11 - Competition law. Competition is a general EU topic that is not addressed in a particular Directive or Regulation related to e-commerce. There have been some high-profile competition cases over the years, including in the formative years the Microsoft Explorer and Windows Media Player cases, and in more recent years the Commission has focused its attention on various activities of the e-commerce giant Google. Magdalena Jozwiak and Sonia Jozwiak-Gorny (Vrije Universiteit Amsterdam, Polish Competition Authority) authored this chapter, which analyses this wide and complex area as it applies specifically to e-commerce.

Chapter 12 - Data Protection and Privacy. In the information society, in particular in the context of e-commerce, personal data plays a central role. Two different legal concepts, both fundamental rights, are data protection and privacy. The national legislation based on Directive 95/46 is still in force, but it will be replaced by the General Data Protection Regulation, published in Spring 2016. Tijmen Wisman (Vrije Universiteit Amsterdam) covers this broad area, including data breach notification, cookies, behavioral targeting and the data subject rights.

\subsection{FOCUS}

One final observation is to outline the focus of this book: European Union regulation of e-commerce. Jurisdictionally speaking this focus is normally restricted to the Member States of the European Union, although in some circumstances a wider focus is applied for example by the European Court of Justice in some cases and it should be noted that the General Data Protection 
Regulation also takes a wider approach. The issues discussed in the various chapters are specifically relevant to any EU Member State, while the principles discussed are applicable in any state with e-commerce regulation. In this respect it is interesting to note that the original aim of the Commission was to start a global dialogue:

Considering the essentially transnational nature of electronic commerce, global consensus needs to be achieved. The Commission will actively pursue international dialogue, involving government and industry, in the appropriate multilateral fora, as well as bilaterally with its main trading partners.

1.33 As with all Internet law-related topics global regulations are ideal, but difficult

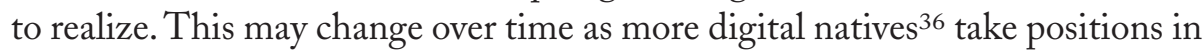
lawmaking and regulatory enforcement bodies. This though is still some way off and therefore for the moment we keep our focus on the European Union, but maybe one day the classic approach to state sovereignty and jurisdiction in relation to e-commerce will be replaced by a globally oriented approach. ${ }^{37}$

37 J. Von Bernstorff, 'Democratic Global Internet Regulation? Governance Networks, International Law and the Shadow of Hegemony', (2003) 9 European Law Journal 511; D.W. Drezner, 'The Global Governance of the Internet: Bringing the State Back In’ (2004) 119 Political Science Quarterly 477 (2004). 